\title{
STRESS ANALYSIS OF STRUCTURAL COMPONENTS OF BIOMIMETIC AUTONOMOUS SUBSEA VEHICLES
}

\author{
SMITHA. K. $\mathrm{K}^{1} \&$ NANDAKUMAR. C. G. ${ }^{2}$ \\ ${ }^{I}$ Department of Naval Architecture and Ship Building Engineering, Sreenarayanagurukulam College of Engineering, \\ Kadayiruppu, Ernakulam, Kerala, India \\ ${ }^{2}$ Department of Ship Technology, Cochin University of Science and Technology, Thrikkakara, Kochi, Kerala, India
}

\begin{abstract}
Biologically inspired autonomous subsea systems are recently being developed, for oceanographic and underwater explorations. The profile of aquatic animals offer least resistance to mobility in marine habitats and is being mimicked to generate biomimetic self sufficient and energy efficient undersea vehicles. Dependence of buoyant force on such self propelled systems forces the application of light weight material for the manufacture of these vehicles. The high mouldabilty, specific stiffness and specific strength of the novel, advanced material, the laminated composite, make it appropriate for the fabrication of the biomimetic self-contained underwater systems. The geometry of the biomimetic subsea systems can be represented, by thin doubly curved shell surface. Absence of classical solutions for the structural responses of general laminated composite thin doubly curved shells under external hydrostatic pressure demand numerical analysis procedures to evaluate the structural behaviour. In this circumstance, the finite element method presents itself as an efficient tool, for the investigation of structural responses of composite doubly curved shells. This paper presents the computation of elastic structural responses of laminated composite spherical shell acting as the supporting structure for the underwater vehicles, using appropriate composite doubly curved triangular shell element

KEYWORDS: Biomimetic, Autonomous Subsea Vehicle, Laminated Composite, Doubly Curved Shells \& External Hydrostatic Pressure
\end{abstract}

Received: Aug 26, 2017; Accepted: Sep 15, 2017; Published: Oct 31, 2017; Paper Id: IJMPERDDEC201711

\section{INTRODUCTION}

Nature has bestowed the aquatic animals with the profile that enables them to move relentlessly beneath the calm and quite ocean, without breaking the silence of the peaceful sea. Biologically diverse outlines of marine environment have inspired human beings in developing biomimetic subsea systems, to explore the unrevealed water body that constitutes the blue planet. Biomimicry has attracted large number of researchers around the world, due to the least energy required, by such shaped vehicles or robots, in navigating through water. Twenty first century has seen human curiosity, to explore and utilize the subsea resources for the advancement of this race. This has led to the development of underwater systems that impersonates the naturally found body shapes of subsea animals and imitates their locomotive systems. Earlier in this century, Vaidyanathanet al (2000) has developed a hydrostatic semi autonomous robot that resembles the body plan of segmental worms, which could be employed for specific marine applications. The profile of fish and its movement systems have inspired mankind, to develop a large number of biomimetic underwater vehicles. Gou (2006), have developed an experimental model, of a biomimetic autonomous underwater vehicle (BAUV) that imitates the profile of a fish with caudal fins. The work has been extended in developing a mooring system for BAUV (Gou, 2008) that is an essential aspect, since the 
batteries are to be charged onshore. The profile and propulsion system of caudal fins have been recreated, in a biomimetic fish like robot, by Heo et al (2007) employing shape memory alloys (SMA) for the fins, the properties of which can be varied with the environment. A similar technology have been employed by Wang et al (2008), in developing a biomimetic fin for a micro robot, using actuated SMA wires, which provide a flexible fin. The outline and the stiffness distribution of a rainbow trout have been mimicked, by Salumae and Kruusmaa (2011) and experiments have been conducted, on the biomimetic fins and concluded that, such artificial fins when employed together with fish like robots could recreate the swimming mode of the fish. Experiments on wide variety of fish robots (Tan, 2012, Ren et al, 2013, Zhou, 2013) that employs the principles of adaptability of the fish, to the aquatic environments and the mobility of the same in the marine atmosphere have been performed recently. Large undulating fins are a gift of god to the great ocean swimmers. The concept of undulating fins together with the geometry of these marine swimmers were mimicked by researchers (Zhang et al, 2007, Hu et al, 2009, Low, 2009, Lauder et al, 2012), in developing near perfect autonomous mobile systems. Differently shaped ocean creatures, the jellyfish, electric ray, blue spotted ray, cuttlefish etc. have inspired the human brain that led to the generation of subsea vehicles (Yeom and Oh, 2009, Krishnamurthy et al, 2010, Zhang et al, 2012, Gao et al, 2014) that acquired the benefits of the geometry of these aquatic lives. Amphibians that live in both aquatic and terrestrial environments have also motivated the intellect of the only thinking creature at earth and guided the way towards the development of amphibious self-sustained systems (Zhang et al, 2006, Georgiades et al, 2009, Shim et al, 2013, Shi et al, 2013, Li et al, 2014), which could progress along the dual atmospheres. Zhang et al, 2013 has developed an amphibian robot, where the underwater motion is established utilizing fins that transform into legs, when moving on land.

The experimental investigations that has been reported were accomplished, on the prototypes manufactured of the material of the era, the laminated composites that is known for its tailor made properties and shapes. Also the use of laminated composites to self-sufficient subsea systems can provide a non-conducting medium by properly selecting the material combinations. The external components of biomimetic aquatic autonomous structural systems are acted upon by hydrostatic pressure, the response analysis of which is an essential and inevitable procedure in the design of such systems. The profile of biomimetic subsea systems are more often curved that can be reproduced utilizing the doubly curved shells. Classical solutions to the structural response of such shells prepared of complex composite material systems, hardly exists demanding the numerical analysis of the biomimetic underwater systems, using finite element method. This paper presents structural analysis of laminated composite subsea shells of the body of biomimetic aquatic robots, using the newly developed doubly curved shell element and provides a solution to the challenges in deep sea engineering.

\section{STRUCTURAL ANALYSIS OF A SPHERICAL SHELL SUBJECTED TO EXTERNAL HYDROSTATIC PRESSURE}

The structural analysis of a laminated composite spherical shell, subjected to external hydrostatic pressure has been accomplished, using a newly developed appropriate composite shell finite element (Smitha, 2014). The doubly curved shell element is based on isoparametric formulation, with a nine noded triangulargeometry having five degrees of freedom per node viz., the three translations and two inplane rotations. The existing strain-displacement relations based on Firstorder Shear Deformation Theory (Reddy, 1997) were modified to include the curvature terms in the shear strains and hence provide a more realistic behavior of the doubly curved shell. The initial ten noded triangular shell elements that happens to be a necessity, to incorporate the complete cubicpolynomials as shape functions is trimmed down to nine noded triangular shell element using the well known finite element technique static condensation (Cook, 1989). The innovative element is 
capable of predicting the layerwise structural responses of a laminated composite thin, doubly curved shell subjected to external hydrostatic pressure made of any number of laminae. The interlaminar shear stresses that play a major role in the failure of laminated composite shells, can be qualitatively estimated by employing this novel finite element. The modified strain-displacement relations are specified as Eqns (1a) and (1b), as presented below.

$$
\begin{aligned}
& \gamma_{\varphi_{\zeta}}=\varphi_{\varphi}+\beta_{5}+\zeta \kappa_{5} \\
& \gamma_{\theta \zeta}=\varphi_{\theta}+\beta_{6}+\zeta \kappa_{6}
\end{aligned}
$$

The terms $\zeta \kappa_{5}$ in (1a) and $\zeta \kappa_{6}$ in $1(\mathrm{~b})$ are derived in the present research work and has been inserted in the existing strain-displacement relations, hence modifying them. The details of derivation of the abovementioned terms have been provided in Smitha (2014). The constitutive relations provided by Reddy (1997), for any number of layers of anisotropic material have been adopted, for the formulation of the finite element. MATLAB has been employed as the tool, for coding the formulations for the shell finite element and the basic steps in the finite element analysis.

Prototype of the spherical underwater robot, developed by Lin et al (2011) is structurally analyzed, using the appropriate finite element developed. The acrylic material is used for the manufacture of $40 \mathrm{~cm}$ diameter subsea spherical autonomous system, with $3 \mathrm{~mm}$ thickness of the external hull. The experimental analysis of the prototype has been conducted, for an external hydrostatic pressure of $0.012 \mathrm{MPa}$ and has sustained the pressure without any damage. Symmetry allows the modeling of the spherical pressure hull by a spherical shell panel; with included angle of 0.7854 radians with symmetric boundary conditions on all four sides of the panel. Figure. 1a below shows the geometry of the spherical shell. The spherical shell panel has been discretized, using a 7x7 meshof the newly developed shell element as shown in Figure 1b. $\mathrm{E}=3200 \mathrm{~N} / \mathrm{mm}^{2}$ and Poisson's ratio=0.35.

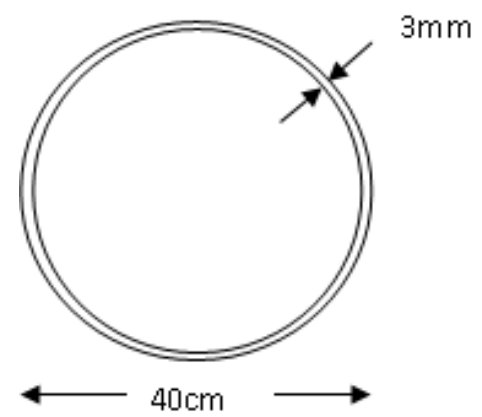

Figure.1a: Thegeometry of the Spherical Shell

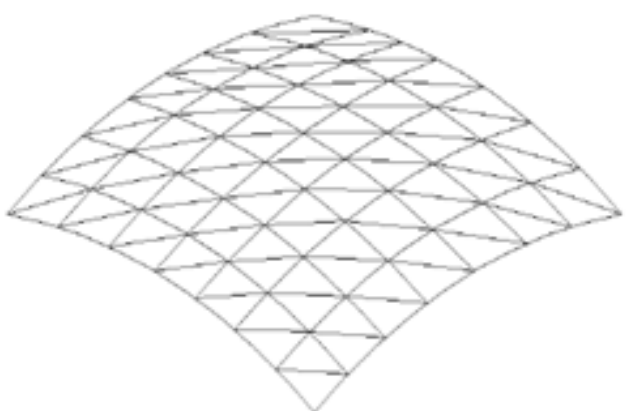

Figure. 1b 7x7 Mesh of the Spherical Shell Panel

A linear static analysis of the shell has been conducted and the results have been presented in the Table 1 below. The same structure has been analysed using the commercial software ANSYS and the results are also presented in Table 1. 
Table 1: Structural Responses of an Acrylic Spherical Shell

\begin{tabular}{|l|c|c|}
\hline \multicolumn{1}{|c|}{ Output } & Authors $(\mathbf{7 x 7})$ Mesh & $\begin{array}{c}\text { ANSYS (30 X30 } \\
\text { Mesh) }\end{array}$ \\
\hline Radial deflection $(\mathrm{mm})$ & 0.0209 & 0.0206 \\
\hline Inplane stress $\sigma_{\varphi \varphi}\left(\mathrm{N} / \mathrm{mm}^{2}\right)$ & 0.4099 & 0.3926 \\
\hline Inplane stress $\sigma_{\theta \theta}\left(\mathrm{N} / \mathrm{mm}^{2}\right)$ & 0.4101 & 0.4013 \\
\hline Inplane shear stress $\tau_{\varphi \theta}\left(\mathrm{N} / \mathrm{mm}^{2}\right)$ & 0 & 0 \\
\hline Transverse shear stress $\tau_{\varphi \mathrm{z}}\left(\mathrm{N} / \mathrm{mm}^{2}\right)$ & 0.0001 & 0 \\
\hline Transverse shear stress $\tau_{\theta \mathrm{z}}\left(\mathrm{N} / \mathrm{mm}^{2}\right)$ & 0 & 0 \\
\hline
\end{tabular}

The same structure has been analyzed, by changing the shell material to cross ply laminated composite of glass epoxy laminae having 9 layers, in order to present the advantage of using such advanced materials. The material properties reported by Kaw (2006) as given below are employed herein.

$\mathrm{E}_{1}=38.6 \mathrm{GPa}, \mathrm{E}_{2}=\mathrm{E}_{3}=8.27 \mathrm{GPa}, \mathrm{G}_{12}=\mathrm{G}_{13}=4.14 \mathrm{GPa}, \mathrm{G}_{23}=2.07 \mathrm{GPa}, v_{12}=0.26$

Table 2 presents the results of the analysis.

Table 2: Structural Responses of Cross Ply Laminated Composite Spherical Shell

\begin{tabular}{|l|c|c|}
\hline Output & Authors (7x7 Mesh) & ANSYS (60x60 Mesh) \\
\hline Radial deflection $(\mathrm{mm})$ & 0.0039 & 0.0043 \\
\hline Inplane stress $\sigma_{\varphi \varphi}\left(\mathrm{N} / \mathrm{mm}^{2}\right)$ & 0.6418 & 0.5657 \\
\hline Inplane stress $\sigma_{\theta \theta}\left(\mathrm{N} / \mathrm{mm}^{2}\right)$ & 0.1692 & 0.1186 \\
\hline Inplane shear stress $\tau_{\varphi \theta}\left(\mathrm{N} / \mathrm{mm}^{2}\right)$ & 0 & 0.0002 \\
\hline $\begin{array}{l}\text { Transverse shear stress } \tau_{\varphi \mathrm{z}} \\
\left(\mathrm{N} / \mathrm{mm}^{2}\right)\end{array}$ & 0 & 0 \\
\hline $\begin{array}{l}\text { Transverse shear stress } \tau_{\theta \mathrm{z}} \\
\left(\mathrm{N} / \mathrm{mm}^{2}\right)\end{array}$ & 0 & 0.0001 \\
\hline
\end{tabular}

The advantage of using laminated composites can be inferred from Table 2, as the deflection has reduced by $84 \%$, on employing cross ply glass epoxy shell.

\section{CONCLUSIONS}

Biomimetic underwater autonomous structure presents an efficient ocean monitoring systems, which extracts the advantages of the biological shape and the mobility features, bestowed on the subsea organisms. Structural responses of a typical spherical underwater vehicle have been established using an appropriate laminated composite doubly curved shell finite element and have been compared with results obtained, using the commercial software ANSYS. The advantage of employing laminated composite material for the manufacture of underwater systems has been ascertained, from the predicted responses of the spherical subsea vehicle.

\section{REFERENCES}

1. Cook R D, Malkus D S, Plesha M E, Concepts and applications of finite element analysis, John Wiley \& Sons, 1989

2. Gao. F, Wang. Z, Wang. Y and Wang. Y, Li. J (2014). "A Prototype of a Biomimetic Mantle Jet Propeller Inspired by Cuttlefish Actuated by SMA Wires and a Theoretical Model for Its Jet Thrust”, Journal of Bionic Engineering, Vol No. 11, pp 412-422.

3. Georgiades. C, Nahon. M, and Buehler. M (2009). "Simulation of an underwater hexapod robot", Ocean Engineering, Vol. No. 36, pp39-47. 
4. Guo. J (2006) “A waypoint-tracking controller for a biomimetic autonomous underwater vehicle”, Ocean Engineering, Vol. No. 33, pp 2369-2380.

5. Guo. J, "Mooring cable tracking using active vision for a biomimetic autonomous underwater vehicle”,13, Journal of Marine Science Technology, 147-153, 2008.

6. Heo. S, Wiguna. T, Park. H.C, Goo.N.S, "Effect of an Artificial Caudal Fin on the Performance of a Biomimetic Fish Robot Propelled by Piezoelectric Actuators”, 4, Journal of Bionic Engineering, 151-158, 2007.

7. Hu.T, Shen.L, Lin.L, Xu.H, "Biological inspirations, kinematics modeling, mechanism design and experiments on an undulating robotic fin inspired by Gymnarchusniloticus”, 44, Mechanism and Machine Theory, 633-645, 2009.

8. Kaw.A.K, Mechanics of Composite Materials, Second Edition, CRC Press, New York, 2006

9. Krishnamurthy.P, Khorrami.F, Leeuw.J.D, Porter.M.E, Livingston.K, Long, Jr.J.H, “An Electric Ray Inspired Biomimetic Autonomous Underwater Vehicle”, Proceedings of American Control Conference, Baltimore, USA, 5224-5229, July, 2010.

10. Lauder.G.V, Lim.J, Shelton.R, Witt.C, Anderson.E, Tangorra.J.L, "Robotic Models for Studying Undulatory Locomotion in Fishes”, Volume 45, No. 4, Marine Technology Society Journal 41-55, 2011.

11. Li.M, Gou.S, Hirata.H, Ishihara.H, "Design and Performance Evaluation of an Amphibious Spherical Robot”, Accepted Manuscript, Robotics and Autonomous Systems.

12. Lin.X, Guo.S, Tanaka.K, Hata.S, "Development of a Spherical Underwater Robot”, Proceedings of the 2011 IEEE/ICME International Conference on Complex Medical Engineering, China, 662-665, 2011.

13. Low.K.H, "Modelling and parametric study of modular undulating fin rays for fish robots" 44, Mechanism and Machine Theory, 615-632, 2009.

14. Reddy J N, Mechanics of laminated composite plates and shells CRC Press, New York, 1997.

15. Ren.Q, Xu.J, Fan.L, Niu.X, “A GIM-Based Biomimetic Learning Approach for Motion Generation of a Multi-Joint Robotic Fish”, 10, Journal of Bionic Engineering,423-433, 2013.

16. Salumae.T, Kruusmaa.M, “A Flexible Fin with Bio-Inspired Stiffness Profile and Geometry”, 8, Journal of Bionic Engineering, 418-428, 2011.

17. Shi.L, Guo.S, Mao.S, Yue.C, Li.M, Asaka.K, "Development of an Amphibious Turtle-Inspired Spherical Mother Robot”, 10, Journal of Bionic Engineering, 446-455, 2013.

18. Shim.H, Jun.B.J, Lee.P.K, “Mobility and agility analysis of a multi-legged subsea robot system”, 61, Ocean Engineering, 8896, 2013.

19. Smitha K K, Finite Element Analysis of Laminated Composite Subsea Shells, Ph.D Thesis, 2014, Cochin University of Science and Technology, Kochi, Kerala

20. Tan.X., “Autonomous Robotic Fish as Mobile Sensor Platforms: Challenges and Potential Solutions”, Volume 45, No. 4, Marine Technology Society Journal 31-40, 2011.

21. Vaidyanathan.R, Chiel.H.J, Quinn. R.D, “A hydrostatic robot for marine applications”, 30, Robotics and Autonomous Systems, 103-113, 2000.

22. Wang.Z, Hang.G, Li.J, Wang.Y, Xiao.K, “A micro-robot fish with embedded SMA wire actuated flexible biomimetic fin”, 144, Sensors and Actuators A, 354-360, 2008. 
23. Yeom.S.W, Oh.I.K, “A biomimetic jellyfish robot based on ionic polymer metal composite actuators”, 18, Smart Materials and Structures, 1-11, 2009.

24. Zhang.W, Guo.S, Asaka.K, “Characteristics Analysis of a Biomimetic Underwater Walking Microrobot”, Proceedings of IEEE International Conference on Robotics and Biomimetics, China, 1600-1605, 2006.

25. Zhang.Y, He. J, Low.K.H, “Parametric Study of an Underwater Finned Propulsor Inspired by Bluespotted Ray”, 9, Journal of Bionic Engineering, 166-176, 2012.

26. Zhang.Y, Jia.L, Zhang.S, Yang.J, Low.K.H, “Computational Research on Modular Undulating Fin for Biorobotic Underwater Propulsor”, 4, Journal of Bionic Engineering, 25-32, 2007.

27. Zhang.S, Liang.X, Xu.L, Xu.M, “Initial Development of a Novel Amphibious Robot with Transformable Fin-Leg Composite Propulsion Mechanisms", 10, Journal of Bionic Engineering, 434-445, 2013.

28. Zhou.C, Hou.Z.G, Cao.Z,Wang.S, Tan.M, "Motion modeling and neural networks based yaw control of a biomimetic robotic fish”, 237, 39-48, 2013. 